\title{
The role of socioeconomic factors on discontinuation of insulin during pregnancy-methodological challenges from a Swedish register-based study
}

\author{
Liwei Zhao ${ }^{1}$ (D) $\cdot$ Carolyn E. Cesta ${ }^{1}$ (D) $\cdot$ Laura Pazzagli $^{1}$ (D) \\ Received: 29 January 2020 / Accepted: 7 May 2020 / Published online: 3 June 2020 \\ (C) The Author(s) 2020, corrected publication 2020
}

\begin{abstract}
Aim Continuous use of antidiabetic medication, especially insulin, is crucial for diabetes management. In pregnancy, adherence to medication is generally low and may also be associated with lower socioeconomic status. However, little is known about discontinuation of insulin in pregnant women and the potential role of socioeconomic factors. Therefore, this study aims to measure the associations between socioeconomic factors and insulin discontinuation during pregnancy in women using insulin prior to the start of pregnancy in Sweden.

Subjects and methods This cohort study identified pregnancies recorded in the Swedish Medical Birth Register from 2006 to 2016 in women receiving insulin prior to the start of pregnancy $(N=6029)$. Discontinuation of insulin was defined as not receiving a refill within 120 days from the previous refill. Associations between discontinuation and socioeconomic factors were investigated via logistic regression. Sensitivity analyses were performed using different definitions of discontinuation.

Results Women discontinued insulin use in $34.2 \%$ of pregnancies. The odds ratios (ORs) of discontinuation of insulin were 1.17 [95\% confidence interval (CI): 1.01-1.37] for women with lower household disposable incomes and 1.14 (95\% CI: 1.01-1.29) for women with lower educational levels. When testing a change in the maximum refill gap from 91 days to 180 days, women with lower educational levels and those born in non-Nordic countries showed greater associations with discontinuation.

Conclusion The definition of discontinuation affects the level of association of socioeconomic factors with discontinuation. Nevertheless, discontinuation of insulin is common in Sweden, especially in the lower socioeconomic groups. The socioeconomic inequality in insulin use behavior is worth noting.
\end{abstract}

Keywords Diabetes mellitus $\cdot$ Insulin $\cdot$ Pregnancy $\cdot$ Socioeconomic factors $\cdot$ Antidiabetic discontinuation $\cdot$ Maximum gap method

\section{Introduction}

Pre-gestational diabetes mellitus is an increasingly common condition among pregnant women (Bardenheier et al. 2015). In clinical guidelines in Sweden and the US, preconception counseling to optimize glucose control is recommended for women with pre-gestational diabetes (American Diabetes Association 2018; Swedish National Board of Health and

Electronic supplementary material The online version of this article (https://doi.org/10.1007/s10389-020-01307-x) contains supplementary material, which is available to authorized users.

Laura Pazzagli

laura.pazzagli@ki.se

1 Centre for Pharmacoepidemiology, Department of Medicine Solna, Karolinska Institutet, 17176 Stockholm, Sweden
Welfare 2015), including recommendations such as diet and lifestyle modification and antidiabetic medication (ADM). Traditionally, guidelines recommend continuing insulin as treatment for pre-gestational diabetes during pregnancy (American Diabetes Association 2018; Swedish National Board of Health and Welfare 2015, 2018). Prevalence of ADM use in pregnancy has also increased in the last decade, and, depending on the country, $2 \%$ to over $5 \%$ of pregnant women use ADM. Oral hypoglycemic agents are increasingly being used, though insulin remains the most common ADM used in pregnancy (Cesta et al. 2019).

However, the majority of Swedish pregnant women perceive using medication during pregnancy as harmful for the infant, and many refrain from medication use (Wolgast et al. 2019). A number of studies have reported a lack of adherence to medical advice, including prescribed medication, by pregnant women with chronic conditions (Lupattelli et al. 2014; 
Matsui 2012; Sawicki et al. 2011), and a Dutch study reported that the prescription rate of most medications for chronic conditions decreased during pregnancy (Bakker et al. 2006). In the case of diabetes this is problematic, as women with uncontrolled diabetes during pregnancy have higher rates of obstetrical complications, perinatal death, and fetal abnormalities (Ludvigsson et al. 2018; Tennant et al. 2014). Pregnancy is also a peculiar time for drug effectiveness. For example, women become less sensitive to insulin, and higher dosages of ADM are needed in late pregnancy to maintain optimal target glucose levels.

Previous studies in non-pregnant populations have shown that discontinuation of ADM was associated with age, ethnicity, finances, medication costs, and tolerance as well as the effectiveness and complexity of the treatment regimen (Capoccia et al. 2016; Nam et al. 2011). A study from 2017 also showed that low socioeconomic status (SES) may lead to poor disease control and consequently increase the risk of developing end-stage renal disease among type 1 diabetes patients in Sweden (Pazzagli et al. 2017). However, few to no studies have investigated changes in insulin use behaviors or the influence of SES on discontinuation of insulin in pregnant women. Therefore, this study aims to describe insulin use and the associations between socioeconomic factors, as proxy for SES, and discontinuation of insulin during pregnancy in diabetic women who started treatment before pregnancy.

\section{Methods}

\section{Data sources and setting}

In this cohort study, data from the Swedish Prescribed Drug Register (PDR), the Longitudinal Integration Database for Health Insurance and Labor Market Studies (LISA by Swedish acronym), the Swedish Medical Birth Register (MBR), and the Swedish National Patient Register (NPR) were linked using the unique individual identification number provided to each resident upon birth or immigration.

\section{Study population}

The study population consisted of all singleton pregnancies lasting longer than 22 weeks from women using insulin prior to pregnancy and delivered from 2006 to 2016 in Sweden. Insulin use was identified using insulin dispensation records in the PDR by anatomical therapeutic chemical (ATC) codes (see Table 3 of the Supplementary Material) from 90 days before pregnancy to the end of the first trimester (i.e., day 97 after the date of the last menstrual period). Pregnancies from women who received any other ADM were excluded. Diagnoses of diabetes subtypes were obtained from the MBR and NPR. A total of 6029 pregnancies in 4344 women was identified.

\section{Definition of discontinuation}

For each pregnancy, the time intervals, or refill gaps, between two consecutive dispensation records in the PDR were calculated. Discontinuation was defined as not refilling insulin within a specified refill gap. According to the Swedish reimbursement system, the maximum amount of medication in one dispensation is a 3-month supply, and therefore 120 days was chosen as the maximum allowed refill gap (Perez-Nieves et al. 2016). To test the impact of the choice of the maximum allowed refill gap on the definition of discontinuation, the proportion of discontinuers was plotted over different maximum refill gaps ranging from 91 to 180 days.

\section{Socioeconomic factors and other factors of interest}

Household disposable income in the year of delivery was dichotomized in such a way that income below the first quintile of the year was classified as low income. Education was categorized according to the number of years of completed education, namely $\leq 9$ years, 2 or 3 years of upper secondary school, and university degree or other higher education. Mother's country of birth was categorized into Nordic and non-Nordic. Maternal age was categorized into $\leq 24$, from 25 to 34 , and $\geq 35$ years. Smoking, cohabitation with a partner, and parity were categorized as binary variables. Body mass index (BMI) was calculated based on maternal weight and height at first antenatal care visit and categorized into underweight or normal $\left(<25 \mathrm{~kg} / \mathrm{m}^{2}\right)$, overweight $(25-$ $\left.29.9 \mathrm{~kg} / \mathrm{m}^{2}\right)$, and obese $\left(\geq 30 \mathrm{~kg} / \mathrm{m}^{2}\right)$, according to the World Health Organization (WHO) classification (World Health Organization 2000).

Diabetes subtype was determined based on a hierarchy of diagnosis due to discrepancies between reporting in the NPR and MBR, with women with at least one type 1 diabetes diagnosis being classified as having type 1 diabetes and women with no type 1 diabetes diagnosis being classified as having type 2 diabetes.

\section{Statistical analysis}

Descriptive statistics were generated to study the distribution of characteristics in the study population overall and specifically within the insulin 'discontinuers' and 'continuers'. Logistic regression was used to investigate the association of SES with discontinuation of insulin during pregnancy, including household disposable income, educational level, cohabitation with a partner, and mother's country of birth as exposures. Odds ratios (ORs) and 95\% confidence intervals (CIs) were estimated. Covariates including pre-pregnancy BMI category, smoking, maternal age, parity, and diabetes subtype were adjusted for in the model. To test how the definition of discontinuation affected the associations, the same regression 
model was fitted using 91 days, 150 days, and 180 days as the maximum refill gaps for defining discontinuation.

Missing values for each variable were categorized as such in the analysis. Data analyses were conducted using RStudio (version 1.1.463), and the dyplr and ggplot2 packages were used for data management and plotting (RStudio Team 2016; Wickham 2016; Wickham et al. 2019).

\section{Results}

From 2006 to 2016, there were 6029 pregnancies where the mother was dispensed insulin, and no other ADM, in the 90 days before pregnancy. In $34.2 \%$ of the pregnancies, insulin was discontinued, and the women were defined as "discontinuers". Table 1 shows the characteristics of the study population. Compared to women who continued insulin throughout pregnancy, women who discontinued had lower parity, lower BMI, and lower income and more often had a diagnosis of type 1 diabetes.

Table 2 lists the associations between the mothers' socioeconomic factors and discontinuation of insulin during pregnancy. After adjusting for maternal age, BMI, parity, smoking, and diabetes subtype, the OR was 1.14 (95\% CI: 1.01-1.29) for women with 2 or 3 years of upper secondary school education compared with women with university or other higher education, while there were no increased odds for women with the lowest level of education. The OR was 1.17 (95\% CI: 1.01-1.37) for household disposable income below the first quintile compared with household disposable income above the first quintile. Non-Nordic-born women had similar odds of discontinuation compared with Nordic-born women. The OR was 1.17 (95\% CI: 0.77-1.76) for women not cohabitating with respect to women cohabitating.

Sensitivity analysis showed that the definition of discontinuation notably affects the proportion of insulin discontinuers in our study population (Fig. 1) with the proportion decreasing by approximately half with every 30 -day increase in the maximum allowed gap. The percentages of discontinuers were $64.5 \%, 34.2 \%, 15.1 \%$, and $6.4 \%$ when the maximum refill gaps were set to 91, 120, 150, and 180 days, respectively.

As the maximum allowed refill gap when set to 150 and 180 days changed the proportion of discontinuers, the strength of the associations between discontinuation and level of education, maternal country of birth, and cohabitation increased (Fig. 2, Table 4 of the Supplementary Material). However, the results for household disposable income changed in a different direction, with discontinuation and low household disposable income showing an association when 91 days and 120 days were the maximum allowed refill gaps, while there was no association when the gap was set to 150 days and 180 days.

\section{Discussion}

In this population-based cohort study, we showed that according to our definitions, up to approximately onethird of women who used insulin before pregnancy discontinued insulin use after the start of pregnancy. Furthermore, discontinuation was associated with socioeconomic factors including lower education level and lower household disposable income.

\section{High proportion of discontinuation of insulin during pregnancy}

The definition of discontinuation assumes that insulin was prescribed and dispensed following regulations within the Swedish reimbursement system, where the maximum amount of medication provided in one dispensation is a 3-month supply. Furthermore, medication can only be refilled after twothirds of the time covered by the previous dispensation has passed (Swedish Parliament Administration 2002). This means that women can refill insulin with 1 month of supply left from the previous dispensation. In addition, insulin has a short expiration time and can only be stored approximately 28 days from the first use (Moore 2018). Therefore, individuals who are continuously using their medication are not likely to postpone the next refill date for long. Hence, the definition of discontinuation was set to 120 days as the maximum gap between refill dates. Based on this definition, results showed a high proportion of discontinuers of insulin during pregnancy, with more than one-third of pregnant women discontinuing their insulin refills. In the sensitivity analysis, $15.1 \%$ and $6.4 \%$ of pregnant women were defined as "discontinuers" when the maximum gap was prolonged to 150 and 180 days, respectively.

Even though the number of discontinuers decreased when allowing for longer refill gaps of 150 and 180 days, it still represents a substantial proportion of mothers and offspring who are exposed to untreated diabetes during pregnancy, thus posing a public health concern. Type 1 diabetes has a low prevalence in the general population and makes up only $10 \%$ of all diabetes cases (Moore 2018). However, by identifying the study population based on insulin use, women in approximately $90 \%$ of the pregnancies in our study population were diagnosed with type 1 diabetes. Counterintuitively, women with a diagnosis of type 1 diabetes showed higher odds of discontinuation of insulin compared with women with type 2 diabetes when the maximum gap was set at 91 days and 120 days. Women with type 1 diabetes are reliant on insulin treatment and risk severe outcomes with discontinuation, such 
Table 1 Descriptive statistics of the study population

\begin{tabular}{|c|c|c|c|}
\hline & $\begin{array}{l}\text { Study population } \\
\mathrm{n}(\%)\end{array}$ & $\begin{array}{l}\text { Continuers } \\
\mathrm{n}(\%)\end{array}$ & $\begin{array}{l}\text { Discontinuers } \\
\mathrm{n}(\%)\end{array}$ \\
\hline & $6029(100.0)$ & $3970(65.8)$ & $2059(34.2)$ \\
\hline \multicolumn{4}{|l|}{ Education level } \\
\hline$\leq 9$ years & $671(11.1)$ & $456(11.5)$ & $215(10.4)$ \\
\hline $2-3$ years of upper secondary school & 2345 (38.9) & $1519(38.3)$ & $826(40.1)$ \\
\hline University or other higher education & $2946(48.9)$ & $1954(49.2)$ & $992(48.2)$ \\
\hline Missing & $67(1.1)$ & $41(1.0)$ & $26(1.3)$ \\
\hline \multicolumn{4}{|l|}{ Household disposable income $e^{\S}$} \\
\hline Below first quintile & $1208(20.0)$ & $771(19.4)$ & $437(21.2)$ \\
\hline Above first quintile & 4817 (79.9) & $3195(80.5)$ & $1622(78.8)$ \\
\hline Missing & $4(0.1)$ & $4(0.1)$ & $0(0.0)$ \\
\hline \multicolumn{4}{|l|}{ Mother's country of birth } \\
\hline Non-Nordic & 775 (12.9) & $529(13.3)$ & $246(11.9)$ \\
\hline Nordic & $5252(87.1)$ & $3440(86.6)$ & $1812(88.0)$ \\
\hline Missing & $2(<0.1)$ & $1(<0.1)$ & $1(<0.1)$ \\
\hline \multicolumn{4}{|l|}{ Cohabiting } \\
\hline No & $111(1.8)$ & $70(1.8)$ & $41(2.0)$ \\
\hline Yes & $5417(89.8)$ & $3558(89.6)$ & $1859(90.3)$ \\
\hline Missing & $501(8.3)$ & $342(8.6)$ & $159(7.7)$ \\
\hline \multicolumn{4}{|l|}{ Pre-pregnancy BMI } \\
\hline Underweight or normal $\left(\leq 24.9 \mathrm{~kg} / \mathrm{m}^{2}\right)$ & $2531(42.0)$ & $1500(37.8)$ & $1031(50.1)$ \\
\hline Overweight (25-29.9 kg/m²) & $1925(31.9)$ & $1285(32.4)$ & $640(31.1)$ \\
\hline Obese $\left(\geq 30 \mathrm{~kg} / \mathrm{m}^{2}\right)$ & $1241(20.6)$ & $950(23.9)$ & $291(14.1)$ \\
\hline Missing & $332(5.5)$ & $235(5.9)$ & $97(4.7)$ \\
\hline \multicolumn{4}{|l|}{ Smoking in early pregnancy } \\
\hline No & $5384(89.3)$ & $3532(89.0)$ & $1852(89.9)$ \\
\hline Yes & $437(7.2)$ & $286(7.2)$ & $151(7.3)$ \\
\hline Missing & $208(3.4)$ & $152(3.8)$ & $56(2.7)$ \\
\hline \multicolumn{4}{|l|}{ Parity } \\
\hline 1 & $2638(43.8)$ & $1716(43.2)$ & $922(44.8)$ \\
\hline $2+$ & $3391(56.2)$ & $2254(56.8)$ & $1137(55.2)$ \\
\hline \multicolumn{4}{|l|}{ Maternal age } \\
\hline$\leq 24$ years & $755(12.5)$ & $485(12.2)$ & $270(13.1)$ \\
\hline $25-34$ years & $3814(63.3)$ & $2498(62.9)$ & $1316(63.9)$ \\
\hline$\geq 35$ years & $1460(24.2)$ & 987 (24.9) & $473(23.0)$ \\
\hline \multicolumn{4}{|l|}{ DM subtype } \\
\hline Type 1 diabetes & $5381(89.3)$ & $3497(88.1)$ & $1884(91.5)$ \\
\hline Type 2 diabetes & $648(10.7)$ & $473(11.9)$ & $175(8.5)$ \\
\hline BMI: mean (SD, number of missing values) & $26.6(5.1,332)$ & $27.2(5.3,235)$ & $25.6(4.5,97)$ \\
\hline Maternal age: mean (SD, number of missing values) & $30.7(5.3,0)$ & $30.8(5.3,0)$ & $30.6(5.3,0)$ \\
\hline
\end{tabular}

Family disposable income (in 1000 Swedish krona): mean (SD, number of missing values) $427.35(249.56,4) \quad 422.2(226.77,4) \quad 437.28(288.23,0)$

BMI: body mass index, DM: diabetes mellitus, Missing: value not available, SD: standard deviation

${ }^{\S}$ Income increases over time and the first quintile of household disposable income was defined per year among women who gave birth in the same year. Household disposable income of each woman was then compared against the first quintile of the corresponding year

as diabetic acidosis, while women with type 2 diabetes may try to control their glucose levels with lifestyle modification or other types of ADM. However, type 2 diabetes is less common among reproductive aged women (Nolan et al. 2011), and the type 2 diabetes patients who use insulin identified in this study population likely represented women with a 
Table 2 Associations between socioeconomic factors and discontinuation of insulin defined by maximum refill gap of 120 days

\begin{tabular}{|c|c|c|}
\hline & Adjusted $\mathrm{OR}^{\S}$ & $95 \% \mathrm{CI}$ \\
\hline \multicolumn{3}{|l|}{ Education level } \\
\hline$\leq 9$ years & 1.00 & $0.81-1.22$ \\
\hline 2 or 3 years of upper secondary school & 1.14 & $1.01-1.29$ \\
\hline University or other higher education & Reference & \\
\hline \multicolumn{3}{|l|}{ Household disposable income } \\
\hline Below first quintile & 1.17 & $1.01-1.37$ \\
\hline Above first quintile & Reference & \\
\hline \multicolumn{3}{|l|}{ Mother's country of birth } \\
\hline Non-Nordic & 1.02 & $0.84-1.23$ \\
\hline Nordic & Reference & \\
\hline \multicolumn{3}{|l|}{ Cohabiting } \\
\hline Yes & Reference & \\
\hline No & 1.17 & $0.77-1.76$ \\
\hline \multicolumn{3}{|l|}{ Pre-pregnancy BMI } \\
\hline Underweight or normal $\left(\leq 24.9 \mathrm{~kg} / \mathrm{m}^{2}\right)$ & Reference & \\
\hline Overweight $\left(25-29.9 \mathrm{~kg} / \mathrm{m}^{2}\right)$ & 0.72 & $0.63-0.81$ \\
\hline Obese $\left(\geq 30 \mathrm{~kg} / \mathrm{m}^{2}\right)$ & 0.45 & $0.38-0.52$ \\
\hline \multicolumn{3}{|l|}{ Smoking in early pregnancy } \\
\hline No & Reference & \\
\hline Yes & 0.97 & $0.78-1.20$ \\
\hline \multicolumn{3}{|l|}{ Parity } \\
\hline 1 & Reference & \\
\hline $2+$ & 1.01 & $0.90-1.13$ \\
\hline \multicolumn{3}{|l|}{ Maternal age } \\
\hline$\leq 24$ years & 0.97 & $0.81-1.16$ \\
\hline 25-34 years & Reference & \\
\hline$\geq 35$ years & 0.96 & $0.84-1.10$ \\
\hline \multicolumn{3}{|l|}{ DM subtype } \\
\hline Type 1 diabetes & Reference & \\
\hline Type 2 diabetes & 0.84 & $0.68-1.02$ \\
\hline
\end{tabular}

BMI: body mass index, CI: confidence interval, DM: diabetes mellitus, OR: odds ratio.

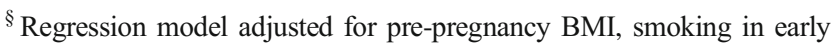
pregnancy, parity, maternal age, and diabetes subtype.

high severity of the disease, who consequently may have higher propensity to follow treatment recommendations.

\section{Socioeconomic factors and discontinuation}

Results suggest that socioeconomic factors, including education and household disposable income, were associated with discontinuation of insulin. This indicates that health expenditures and health literacy may be important factors in whether a woman continues medication during pregnancy (Schillinger et al. 2002; Shavers 2007). In Sweden, insulin and maternal healthcare are free, and there is high-cost protection for healthcare visits and prescribed drugs (Swedish Parliament Administration 1989). However, the working-age household poverty rate in Sweden varied between $13.9 \%$ and $17.9 \%$ from 2004 to 2016 (OECD 2013), and several studies have concluded that socioeconomic factors are still associated with accessibility to healthcare in Sweden (Burström 2009; Ferro and Kristiansson 2011). For example, some families can still be sensitive to the health expenditures that are not covered, such as the cost of travel to clinics for women with lower income and living in geographically remote areas of the country. In general, poor availability of information and general health literacy in pregnant women is problematic, with a recent study reporting that the majority of pregnant women in Sweden perceive medication use during pregnancy as harmful (Wolgast et al. 2019). Although insulin is recommended for pre-gestational diabetes during pregnancy in guidelines and insulin is considered safe in pregnancy (American Diabetes Association 2018; Swedish National Board of Health and Welfare 2015, 2018), limited knowledge among pregnant women about insulin safety may lead to discontinuation (Donelle et al. 2008).

While no association was found between discontinuation and maternal country of birth, being born outside of a Nordic country may still influence a woman's healthcare seeking culture, social support, the ability to communicate with clinical staff related to language barriers, and knowledge about the Swedish healthcare system.

Notably, the choice of maximum allowed refill gap influenced the strength of the associations between discontinuation and socioeconomic factors. The results for the socioeconomic factors showed higher odds of discontinuation when a longer maximum refill gap was used to define discontinuation. The trend of increasing ORs was likely to be related to misclassification of the outcome. With a short maximum refill gap of 91 days, discontinuation is likely to be overestimated because individuals may still have remaining insulin from the previous dispensation, and it may take a longer time to refill the next dispensation. Misclassification is likely to be non-differential since the regulations on prescriptions are the same for all socioeconomic groups. Non-differential misclassification of the outcome would result in a dilution of the associations between socioeconomic factors and discontinuation towards null, closer to $\mathrm{OR}=1$. However, as the definition for discontinuation was relaxed with longer maximum allowed refill gaps of 150 days or 180 days, the difference between high and low SES increased. This trend of increased ORs supports the hypothesis that socioeconomic factors and discontinuation of insulin during pregnancy are associated.

\section{Strength and limitations}

This cohort study is based on data from nationwide population registers where the data were recorded at the time of clinical 
Fig. 1 Percentage of discontinuers when discontinuation was defined by different maximum refill gaps. Not refilling within the maximum refill gap was categorized as "discontinuer"

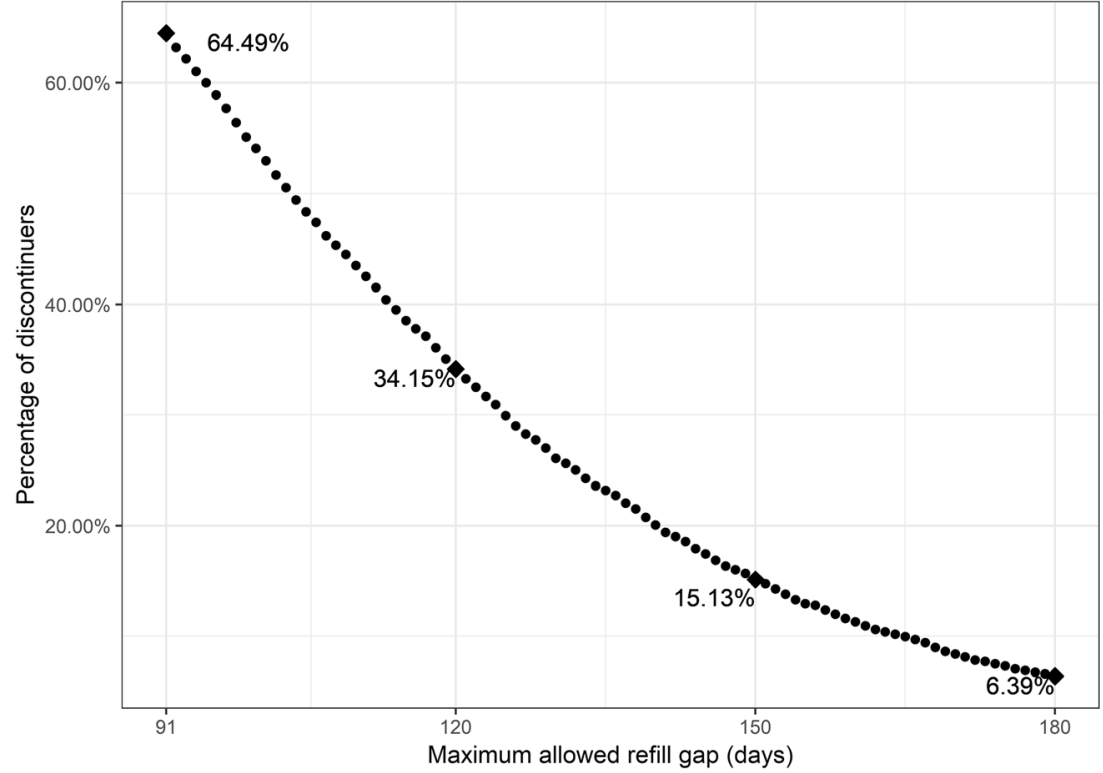

care, resulting in no recall bias or loss to follow-up. While it is known that women who are pregnant often discontinue taking their medication, this study is one of the few which specifically investigates the association between discontinuation of insulin and socioeconomic factors during pregnancy.

However, the PDR contains only recorded dispensations, and the assumption made in this study is that the dispensed medication was actually used by the women in the study population. While the effort to continuously refill a prescription may provide some assurance that the medication is consumed, we could not formally study adherence per se. This is a limitation of using observational data for studying medication use and entails multiple methodological challenges and assumptions which need to be made by investigators (Pazzagli et al. 2018). Additionally, the MBR only records pregnancies lasting
Fig. 2 ORs and 95\% CIs for associations between socioeconomic factors and discontinuation of insulin under different definitions of discontinuation

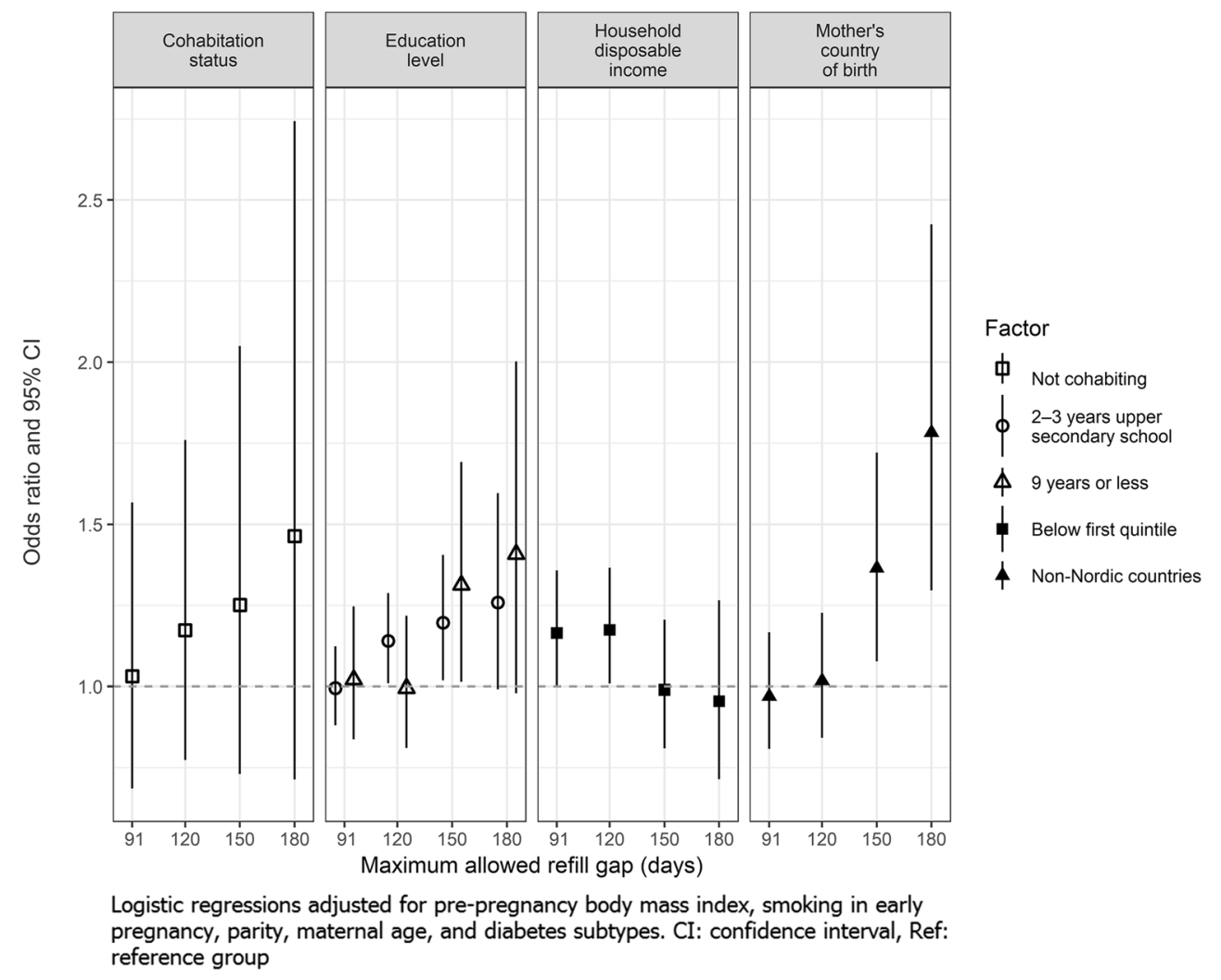


longer than 22 weeks. Therefore, women who have a miscarriage due to uncontrolled glucose levels as a consequence of discontinuation of insulin were not included in the study population.

Another limitation is the potential for misclassification of the diagnoses of diabetes subtypes. There were often discrepancies between diabetes diagnoses recorded in the MBR and the NPR. Therefore, a hierarchy of type 1 diabetes over type 2 diabetes was used when assigning the diagnoses to the study population because of the clinical complexity of deriving a type 1 diabetes diagnosis.

\section{Conclusions}

The maximum gap method is an appropriate approach for measuring discontinuation of insulin during pregnancy. However, the choice of the maximum allowed refill gap affects the magnitude of results of the association between socioeconomic factors and discontinuation. Nevertheless, discontinuation of insulin in pregnancy is common in Sweden, and the socioeconomic inequality in medication use behaviors is worth noting.

Acknowledgements Special gratitude is extended to Helle Kieler for her valuable support during the development of this research work. This study was conducted within the Nordic Pregnancy Drug Safety Study consortium and supported by a grant from NordForsk.

Authorship contribution statement All authors whose names appear on the submission:

(1) made substantial contributions to the conception and design of the work; the acquisition, analysis, and interpretation of data;

(2) drafted the work and revised it critically for important intellectual content;

(3) approved the version to be published;

(4) agree to be accountable for all aspects of the work in ensuring that questions related to the accuracy or integrity of any part of the work are appropriately investigated and resolved.

Funding Information Open access funding provided by Karolinska Institute.

\section{Compliance with ethical standards}

Ethical approval This study was approved by the Swedish Ethical Review Authority.

Conflict of interest The authors declare that they have no conflict of interest.

Disclosures LZ was a master student at Karolinska Institutet when conducting this study and declares no competing interests. CEC and LP are employees at the Centre for Pharmacoepidemiology, which receives grants from several entities (pharmaceutical companies, regulatory authorities, contract research organizations) for the performance of drug safety and drug utilization studies, unrelated to this work.
Open Access This article is licensed under a Creative Commons Attribution 4.0 International License, which permits use, sharing, adaptation, distribution and reproduction in any medium or format, as long as you give appropriate credit to the original author(s) and the source, provide a link to the Creative Commons licence, and indicate if changes were made. The images or other third party material in this article are included in the article's Creative Commons licence, unless indicated otherwise in a credit line to the material. If material is not included in the article's Creative Commons licence and your intended use is not permitted by statutory regulation or exceeds the permitted use, you will need to obtain permission directly from the copyright holder. To view a copy of this licence, visit http://creativecommons.org/licenses/by/4.0/.

\section{References}

American Diabetes Association (2018) 13. Management of diabetes in pregnancy: Standards of medical care in diabetes-2018. Diabetes Care 41:S137-S143. https://doi.org/10.2337/dc18-S013

Bakker MK, Jentink J, Vroom F et al (2006) Maternal medicine: drug prescription patterns before, during and after pregnancy for chronic, occasional and pregnancy-related drugs in the Netherlands. BJOG Int J Obstet Gynaecol 113:559-568. https://doi.org/10.1111/j.14710528.2006.00927.x

Bardenheier BH, Imperatore G, Devlin HM et al (2015) Trends in prepregnancy diabetes among deliveries in 19 US states, 2000- 2010. Am J Prev Med 48:154-161. https://doi.org/10.1016/j.amepre.2014. 08.031

Burström B (2009) Market-oriented, demand-driven health care reforms and equity in health and health care utilization in Sweden. Int J Health Serv 39:271-285. https://doi.org/10.2190/HS.39.2.c

Capoccia K, Odegard PS, Letassy N (2016) Medication adherence with diabetes medication: a systematic review of the literature. Diabetes Educ 42:34-71. https://doi.org/10.1177/0145721715619038

Cesta CE, Cohen JM, Pazzagli L et al (2019) Antidiabetic medication use during pregnancy: an international utilization study. BMJ Open Diabetes Res Care 7:e000759. https://doi.org/10.1136/bmjdrc2019-000759

Donelle L, Arocha JF, Hoffman-Goetz L (2008) Health literacy and numeracy: key factors in cancer risk comprehension. Chronic Dis Can $29: 8$

Ferro A, Kristiansson PMD (2011) Ecology of medical care in a publicly funded health care system: a registry study in Sweden. Scand J Prim Health Care 29:187-192. https://doi.org/10.3109/02813432.2011. 585546

Ludvigsson JF, Neovius M, Söderling J et al (2018) Periconception glycaemic control in women with type 1 diabetes and risk of major birth defects: population based cohort study in Sweden. BMJ 362: k2638

Lupattelli A, Spigset O, Nordeng H (2014) Adherence to medication for chronic disorders during pregnancy: results from a multinational study. Int J Clin Pharm 36:145-153. https://doi.org/10.1007/ s11096-013-9864-y

Matsui D (2012) Adherence with drug therapy in pregnancy. Obstet Gynecol Int 2012:1-5. https://doi.org/10.1155/2012/796590

Moore LE (2018) Diabetes in pregnancy: the complete guide to management. Springer. https://doi.org/10.1007/978-3-319-65518-5

Nam S, Chesla C, Stotts NA et al (2011) Barriers to diabetes management: patient and provider factors. Diabetes Res Clin Pract 93:1-9. https://doi.org/10.1016/j.diabres.2011.02.002

Nolan CJ, Damm P, Prentki M (2011) Type 2 diabetes across generations: from pathophysiology to prevention and management. Lancet 378 : 169-181. https://doi.org/10.1016/S0140-6736(11)60614-4 
OECD (2013) Income Distribution, OECD Social and Welfare Statistics (database). https://doi.org/10.1787/data-00654-en

Pazzagli L, Linder M, Zhang M et al (2018) Methods for time-varying exposure related problems in pharmacoepidemiology: an overview. Pharmacoepidemiol Drug Saf 27:148-160. https://doi.org/10.1002/ pds. 4372

Pazzagli L, Möllsten A, Waernbaum I (2017) Marginal structural model to evaluate the joint effect of socioeconomic exposures on the risk of developing end-stage renal disease in patients with type 1 diabetes: a longitudinal study based on data from the Swedish childhood diabetes study group. Ann Epidemiol 27:479-484. https://doi.org/10. 1016/j.annepidem.2017.07.003

Perez-Nieves M, Kabul S, Desai U et al (2016) Basal insulin persistence, associated factors, and outcomes after treatment initiation among people with type 2 diabetes mellitus in the US. Curr Med Res Opin 32:669-680. https://doi.org/10.1185/03007995.2015.1135789

RStudio Team (2016) RStudio: integrated development environment for R. RStudio, Inc., Boston, MA

Sawicki E, Stewart K, Wong S et al (2011) Medication use for chronic health conditions by pregnant women attending an Australian maternity hospital: medication use during pregnancy. Aust N Z J Obstet Gynaecol 51:333-338. https://doi.org/10.1111/j.1479-828X.2011. 01312.x

Schillinger D, Grumbach K, Piette J et al (2002) Association of health literacy with diabetes outcomes. JAMA 288:475-482. https://doi. org/10.1001/jama.288.4.475

Shavers VL (2007) Measurement of socioeconomic status in health disparities research. J Natl Med Assoc 99:1013-1023

Swedish National Board of Health and Welfare (2015) Nationella riktlinjer för diabetesvård: stöd för styrning och ledning. Socialstyrelsen, Stockholm
Swedish National Board of Health and Welfare (2018) Nationella riktlinjer för diabetesvård - Stöd för styrning och ledning. Socialstyrelsen, Stockholm

Swedish Parliament Administration (2002) Förordning (2002:687) om läkemedelsförmåner m.m. Svensk författningssamling 2002:2002: 687 t.o.m. SFS 2018:997 - Riksdagen. https://www.riksdagen.se/ sv/dokument-lagar/dokument/svensk-forfattningssamling/ forordning-2002687-om-lakemedelsformaner-mm_sfs-2002-687. Accessed 26 May 2019

Swedish Parliament Administration (1989) Kostnadsfritt insulin Motion 1988/89:Sf311 av Agne Hansson och Marianne Jönsson (båda c) Riksdagen. https://www.riksdagen.se/sv/dokument-lagar/ dokument/motion/kostnadsfritt-insulin_GC02Sf311. Accessed 26 May 2019

Tennant PW, Glinianaia SV, Bilous RW et al (2014) Pre-existing diabetes, maternal glycated haemoglobin, and the risks of fetal and infant death: a population-based study. Diabetologia 57:285-294

Wickham H (2016) ggplot2: Elegant Graphics for Data Analysis. Springer-Verlag New York

Wickham H, François R, Henry L, Müller K (2019) dplyr: A Grammar of Data Manipulation

Wolgast E, Lindh-Åstrand L, Lilliecreutz C (2019) Women's perceptions of medication use during pregnancy and breastfeeding - a Swedish cross-sectional questionnaire study. Acta Obstet Gynecol Scand https. https://doi.org/10.1111/aogs.13570

World Health Organization (2000) Obesity: preventing and managing the global epidemic: report of a WHO consultation. Geneva

Publisher's note Springer Nature remains neutral with regard to jurisdictional claims in published maps and institutional affiliations. 